\title{
OBJECTIFIKASI DIRI TUBUH DAN EGO DIRI DALAM FOTO KONSEPTUAL
}

\author{
Purwastya Pratmajaya Adi L ${ }^{1}$, St. Andre Triadiputra ${ }^{2}$ \\ Program Studi Fotografi \\ Institut Seni Indonesia (ISI) Surakarta \\ ${ }^{1}$ Email: purwastya@isi-ska.ac.id, \\ 2Email: andre@isi-ska.ac.id
}

\begin{abstract}
Objectification is a way to block things that are not supposed to be objects, which often in practice is not generally realized by those who become objects or make them become objects. The human body that appears in photographic imagery in modern life, becomes an appropriate example of how the collective unconsciousness of objectification practices is carried out and produced continuously. This unconsciousness will have an impact on human inability to control and master, and in other perspectives it will also build negative representations of the body and itself. In this work the collective unconscious is accommodated by the ego which then becomes personal awareness, where personal awareness will be conceptualized in the picture frame. This artistic research is interested in conducting an in-depth investigation of the behaviors of unconsciousness of objectification, especially those relating to the human body and self, then explored and used as ideas and foundations for the creation of photographic works. The choice of approach to realize this idea, will use conceptual photography which emphasizes the expression or context of the personal interpretation of the photo artist on a phenomenon as the basis of ideas and main ideas in the creation of his photographic artwork.
\end{abstract}

Keywords: Self Objectification, Body and Ego, Conceptual Photos

\section{Pendahuluan}

\section{Latar Belakang}

Memperbincangkan sejarah perkembangan instrumen fotografi beserta praktek penggunaannya, tidak dapat begitu saja melepaskan dari persepektif yang melihat medium ini sebagai media yang digunakan oleh masyarakat untuk menampilkan gambaran objektifatas dirinya. Sejarah mencatat, salah satu alasan yang membuat fotografi mendapatkan tempat mapan di kalangan para naturalis dan ilmuwan, adalah kepiawaian medium foto untuk membawa serta objektivitas dalam gambar yang direkamnya. Cerita tentang kemampuan medium foto yang mampu menyuguhkan realitas seperti apa adanya, hingga hari ini masih terus diproduksi, berkembang dan dipercayai.
'No pictures, Hoax!', slogan yang muncul dan dikumandangkan oleh masyarakat modern. Bersanding dengan peran medium tersebut yang digunakan untuk mengabsahkan suatu hal, kejadian maupun pengalaman seseorang dalam kehidupan sehari-harinya, ungkapan slogan itu seolah menjadi gambaran nyata atas mengakarnya kepercayaan dan persepsi masyarakat terhadap objektivitas medium foto.

Seiring perjalanan waktu, muncul alasan lain yang juga turut mendongkrak populeritas penggunaan medium fotografi di masyarakat, yaitu kemampuannya untuk membentuk (baca: merekayasa) ulang realitas, menyesuaikan dan disesuaikan dengan keinginan dari pembuatnya. 
Sifat alami medium foto yang selalu mencari dan menampilkan sesuatu yang 'indah', ditopang kepercayaan yang terlanjur mapan atas objektivitas 'realitas' hasil perekamannya, membuat medium foto menjadi leluasa untuk digunakan sebagai media yang menampung dan mempermainkan hasrat serta obsesi kedirian dari pembuatnya. Wacana pengetahuan atas foto, kemudian kembali menemukan formulasi barunya. Foto dianggap sebagai medium yang tidak bebas nilai, sarat makna, subyektif dan menjelma menjadi medium yang penuh dengan intrik kuasa dan kepentingan.

Foto, dalam perspektif yang lain, berkembang menjadi alat kontrol dan praktek untuk mengobjektifikasikan diri sendiri maupun diri manusia lain oleh manusia yang lain. Merujuk pada definisi yang dibuat oleh Calogero (2012: 574), pengobjefikasian merupakan cara memperlakukan dan membuat sesuatu yang seharusnya bukan suatu objek menjadi objek, yang kemudian bisa digunakan, dimanipulasi, dikontrol dan diketahui melalui penampakan fisiknya. Diskusi yang diperbincangkan dalam pembentukan teori self-objectification berkaitan dengan isu gender yang mengkaitkannya dengan konsep tubuh perempuan, pemaknaan dan representasinya yang seringkali berujung dalam kerangka konsekuensi yang negatif di dalam sistem sosial di masyarakat. Seringkali pula praktek objektifikasi merupakan perilaku yang tidak disadari, baik oleh pelakunya maupun mereka yang dijadikan sebagai objek. Meskipun tidak menutup kemungkinan adanya hubungan antara wacana yang diperbincangkan dalam teori tersebut dengan karya yang dihasilkan, tetapi penelitian ini tidak menggunakan secara langsung pandangan gender sebagai ide utamanya.

Basis penciptaan dari penelitian artistik ini, lebih menitikberatkan pada perspektif yang melihat gejala umum dari objektifikasi sebagai praktek yang 'membendakan (mengobjekkan)' sesuatu yang seharusnya bukan suatu objek, yaitu ego dan tubuh manusia dengan melalui pendekatan fotografi konseptual. Praktek objektivikasi diri manusia, menjadi bagian tidak terpisahkan dari sejarah panjang praktek fotografis, dan menjadi semakin gegap gempita di masyarakat modern, terutama ketika melihat aktivitas fotografis bernama selfie. Oxford Dictionaries (2013: 1) mendefinisikan kata ini sebagai sebuah foto seseorang yang dibuat sendiri oleh orang tersebut dengan menggunakan smartphone atau webcam dan kemudian hasil akhirnya diunggah ke media sosial. Pada praktek dewasa ini, produksi foto selfie tidak lagi menggantungkan pada pemakaian kamera yang terdapat dalam smartphone, melainkan juga menggunakan peralatan perekaman foto profesional.

Seiring dengan popularitasnya, selfie berkembang menjadi kosa kata baku yang seolah menunjukkan hubungan privat antara kamera dengan tubuh dan diri manusia. Pandangan umum, seringkali menempatkan praktek foto selfie dalam konteks pemerdekaan diri manusia dari kuasa kamera atau privatisasi atas tubuh dan diri manusia melalui medium foto. Akan tetapi, bagi peneliti, aktivitas fotografis selfie ini menjadi contoh dari bentuk ketidaksadaran para pelakunya, bahwa mereka telah terjebak dalam ruang objektifikasi atas diri mereka sendiri. Pandangan peneliti, dipengaruhi oleh pendapat Synnott (2003), yang melihat bahwa tubuh dan diri manusia adalah tubuh dan diri yang dikonstruksikan oleh kuasa yang lain. Tubuh dan diri personal manusia tidak pernah menjadi milik esklusif dari individu tersebut, melainkan selalu menjadi komoditas yang dibentuk dan direkayasa oleh sistem sosial dan budayanya. Peneliti memperhatikan bahwa ketidaksadaran kolektif atas praktek objektivikasi atas tubuh dan diri, seperti yang terjadi dalam kasus foto selfie, menjadi permasalahan tersendiri dalam kehidupan sosial masyarakat. Peneliti melihat permasalahan tersebut menarik untuk dikupas dan dibahasakan dengan medium yang sama tetapi dilandasai dengan cara pandang yang 
kontradiktif, yaitu kesadaran kritis terhadap praktek objektivisasi dari tubuh dan diri manusia serta kesukarelaan untuk tubuh dan dirinya diobjektivikasikan. Kesukarelaan tersebut dilandasi oleh pengetahuan bahwa tubuh selalu menjadi produk dari sistem sosial yang dianut oleh masyarakat hari ini.

Tujuan utama penelitian kekaryaan ini adalah menghasilkan karya foto yang menyandarkan pada nilai estetis sehingga dapat diapresiasi dan membuka kesadaran kritis masyarakat luas. Karya ini bukan hanya menitik beratkan pada pertimbangan teknis fotografi saja, akan tetapi juga memperhatikan konteks sosial yang terjadi dalam masyarakat, terutama berkaitan dengan ketidaksadaran kolektif dalam praktek representasi diri mereka dalam bentukan foto selfie.

\section{Metode Penciptaan}

Fox (2012: 6) memperhatikan bahwa secara historis, referensi dari perpustakaan, museum serta arsip-arsip seringkali menjadi tempat yang digunakan oleh para seniman dan fotografer untuk menemukan dan memperkuat ide dan gagasannya. Secara umum Fox menjelaskan bahwa proses kerja dalam pengembangan proyek karya seni foto dilakukan melalui proses penemuan pengetahuan yang dihasilkan atas eksplorasi mediumnya serta penyelidikan mendalam terhadap teori dan sejarah fotografi. Selain itu, seniman juga dituntut untuk melakukan observasi dengan menjadikan dunia sebagai tempat yang seolaholah baru sehingga membuat mereka menjadi tertarik untuk melakukan pengamatan terhadap semua hal di dalam dunianya tersebut. Riset yang dilakukan untuk membentuk sebuah ide dan gagasan penciptaan karya fotografi, juga dimungkinkan untuk berkembang ketika seorang seniman terlibat perbincangan dan diskusi yang intens dengan komunitas maupun orang-orang yang dapat membantu mengembangkan idenya. Selain itu, refleksi yang dilakukan untuk melihat diri sendiri serta memperhatikan dan mempelajari karya-karya foto dari seniman yang lain untuk digunakan sebagai referensi, perlu ditempatkan sebagai aktivitas yang penting untuk dilakukan.

Proses penciptaan yang dijabarkan oleh Fox (2012) di atas, digunakan sebagai pondasi metodologi dalam penelitian artistik ini. Sebagai langkah awal, penelitian ini melakukan pengumpulan bahan referensi maupun karya acuan, yang dapat digunakan sebagai literatur pendukung. Bahan referensi pustaka serta visual yang telah terkumpul, diseleksi, diamati dan dikelompokkan berdasarkan atas kebutuhan. Pada saat bersamaan, dilakukan observasi terhadap alam sekitar yang kemudian diperbandingkan dengan hasil pemikiran kritis yang dibangun berdasarkan referensi acuan serta refleksi personal. Untuk memperkuat dan menemukan ide gagasan yang segar serta mendapatkan pemahaman bersama, proses Brain Storming dilakukan secara terus menerus oleh para anggota peneliti. Temuan gagasan dan ide tersebut kemudian diperas untuk divisuaisasikan menjadi karya fotografi.

\section{Hasil Dan Pembahasan}

\section{A. Proses Penciptaan Karya}

Pilihan lokasi yang digunakan sebagai latar bagi penciptaan karya penelitian artistik ini, dilakukan di kota Solo dan sekitarnya.Hal tersebut terutama berkaitan dengan efektifitas produksi serta kecocokan narasi karya foto yang ingin digapai. Sedangkan untuk proses yang dilakukan untuk pembuatan karya dalam penelitian artistik ini dapat dijabarkan sebagai berikut:

\section{Observasi}

Observasi dilakukan dengan studi dokumentasi. Sugiyono (2009), mendefinisikan dokumen sebagai catatan peristiwa yang sudah berlalu, yang berbentuk tulisan, gambar atau karya-karya monumental seseorang. Adapun 
bentukan proses pendokumentasian yang dilakukan peneliti adalah:

\section{a. Dokumentasi berbentuk tulisan}

Dokumentasi berupa tulisan yang berhasil dikumpulkan berkaitan dengan buku maupun artikel yang membahas tentang tubuh, objektifikasi diri serta fotografi konseptual. Selain referensi pustaka berbentuk buku, peneliti juga mencari dokumen berupa tulisan kuratorial yang menyangkut topik gagasan karya. Pada umumnya, dokumen kuratorial dari karya fotografi tertentu, didapatkan melalui laman web seniman terkait. Berikut adalah dokumen tulisan kuratorial dari pameran salah satu seniman yang juga digunakan sebagai karya acuan :

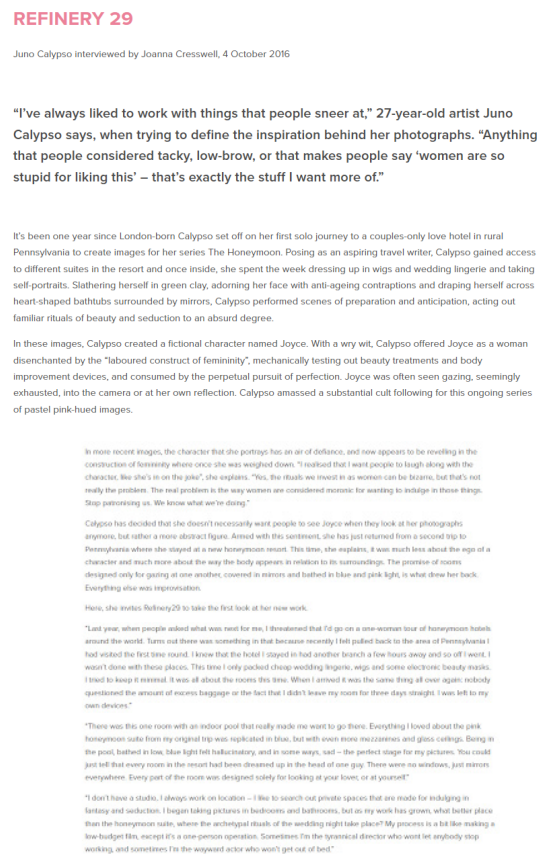

Gambar 3. Dokumen kurasi karya Callypso Sumber Data: https://www.junocalypso.com/text/

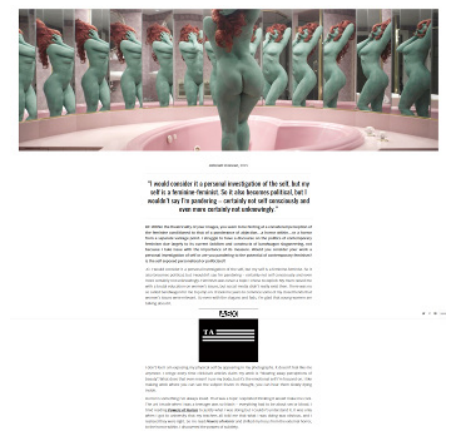

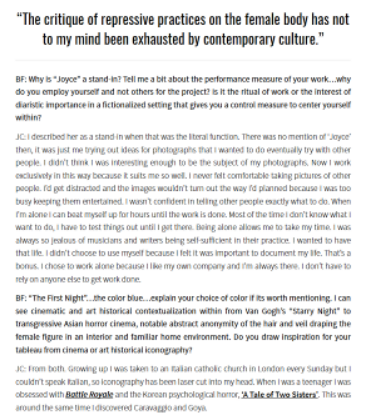

Gambar 1. Dokumen kurasi karya Callypso Sumber Data: http://www.americansuburbx. com/2016/03/five-uneasy-pieces-aninterview-with-juno-calypso.html

Aesthetica
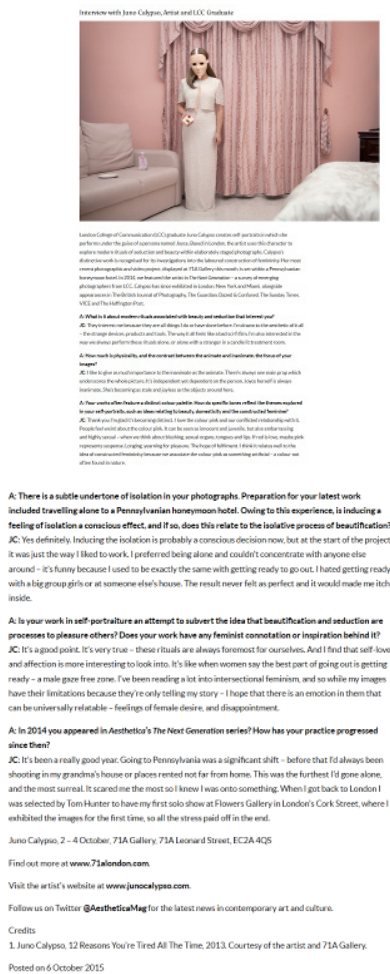

Gambar 2. Dokumen kurasi karya Callypso Sumber Data: http://www. aestheticamagazine.com/ interview-with-juno-calypso-artist-andlcc-graduate/

1). Dokumentasi berbentuk karya acuan: Pendokumentasian ini dititikberatkan pada karya dengan genre fotografi konseptual yang menggunakan tubuh sebagai objek utamanya. Dokumen karya foto tersebut, antara lain: 


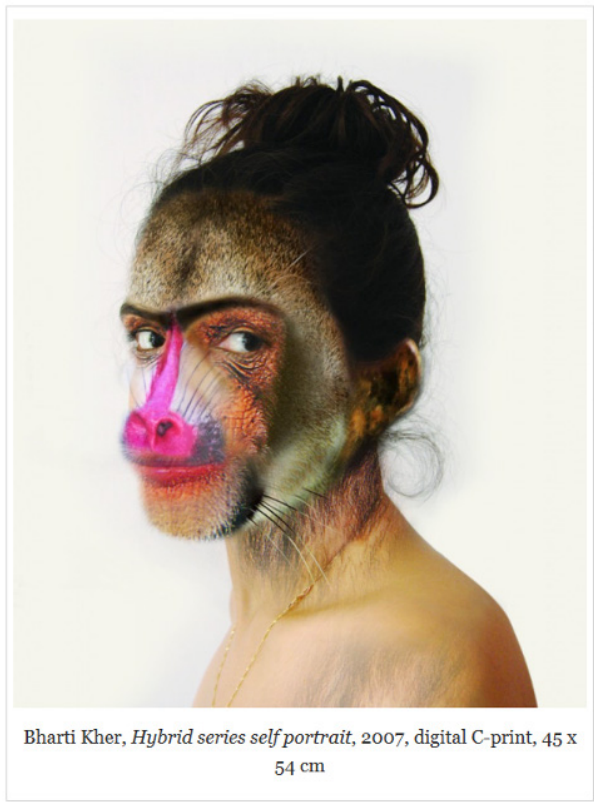

Gambar 3. Dokumen foto karya Bharti Kher, Hybrid series self portrait, 2007 Sumber Foto: https://artiris.wordpress. $\mathrm{com} / \mathrm{tag} /$ feminism/

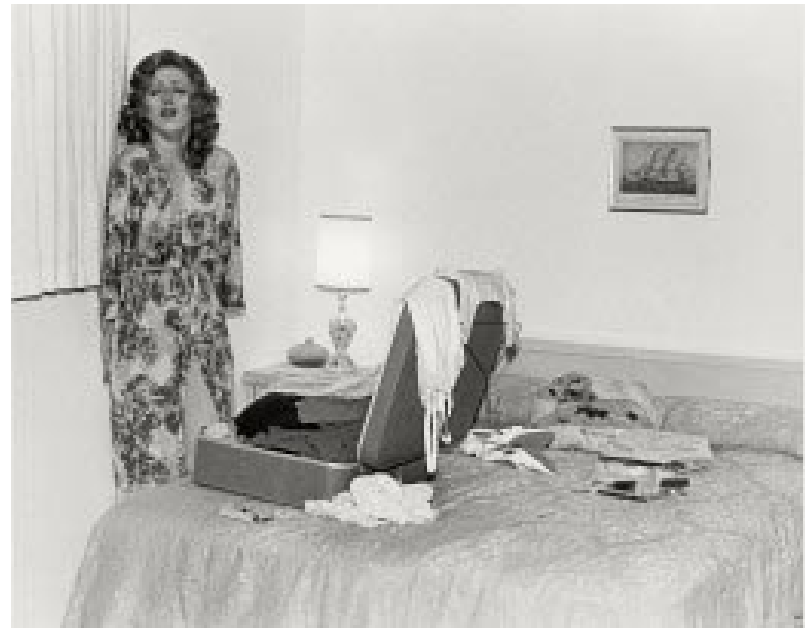

Gambar 4. Dokumen foto karya Chindy

Sherman, Untitled Film Style, 1978

Sumber Foto: https://www.moma.org/interactives/ exhibitions/2012/cindysherman/gallery/chronology/

Setelah semua dokumen terkumpul dan dilakukan pengamatan, muncul persepsi dalam diri peneliti. Abdullah dan Ainon (dalam Hamid, 2007) menerjemahkan persepsi sebagai tafsiran atas apa yang dilihat dengan mata. Persepsi merupakan pemaknaan melalui visualitas mata. Melalui persepsi internal dalam diri peneliti, didapatkan hasil berupa rancangan rencana untuk memakai tubuh menjadi objek utama pengkaryaan dan memakainya menjadi medium penyampaian pesan kritis terhadap perilaku manusia dalam kehidupan sosial melalui pengobjektifikasiannya. Selain proses mempersepsikan dokumen foto, peneliti juga menyerap pengalaman dalam mengamati kejadian atau peristiwa yang terjadi di masyarakat yang karena sifat kekiniannya, cukup menarik untuk digunakan sebagai sub tema. Pengalaman tersebut, kemudian dikombinasikan dan digabungkan dengan daya produktif, beserta persepsi yang menyertainya, untuk membentuk gambaran dan imaji baru yang belum pernah dilihat secara riil sehingga dapat dipresentasikan dan difigurasikan menjadi karya foto (Tedjoworo 2001).

Setelah mempersepsikan dokumen dan pengamatan peristiwa sosial yang terjadi di tengah masyarakat, muncul sebuah ide tentang pesan yang akan dibuat peneliti dalam karyanya. Pesan yang akan disampaikan adalah tubuh manusia yang mempunyai sifat kebinatangan. Adapun sifat-sifat yang manusia yang dimiliki seperti binatang adalah manusia mempunyai sifat "buas" yang mempunyai sifat kejam, galak, liar dan bengis (https:// kbbi.web.id/buas). Sedangkan penentuan sifat manusia yang "buas", diperoleh melaluil pengamatan berbagai kejadian yang terjadi di tengah masyarakat saat ini, yaitu : saling membunuh, perebutan kekuasaan, friksi yang tidak berkesudahan dan lain sebagainya.

\section{a) Eksplorasi}

Setelah proses pertama selesai dilakukan, maka langkah selanjutnya adalah menentukan dan mengerjakan proses visualisasi yang menggunakan sketsa sebagai acuan. Sketsa dibuat sebagai rancangan awal untuk menuangkan ide dan gagasan tertentu ke 
dalam karya seni (fotografi). Elemen rancangan pada sketsa bisa meliputi komposisi, skala dan penyinaran. (www.edutafsi.com). Di bawah ini adalah sketsa yang dilakukan peneliti :

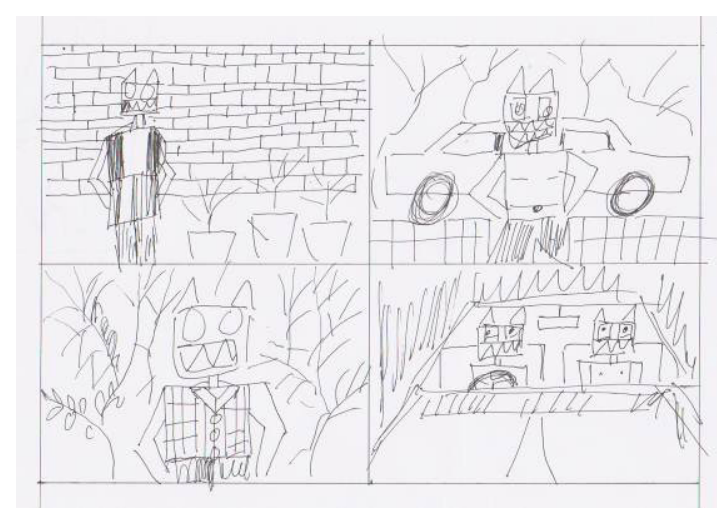

Gambar 5. Sketsa awal yang dilakukan penulis

b) Eksperimen

Eksperimen dilakukan pada saat pemotretan yaitu melalui penataan cahaya, dengan menggunakan tehnik mix light, yaitu mencampurkan sumber cahaya alami, matahari dengan sumber cahaya buatan, flash.

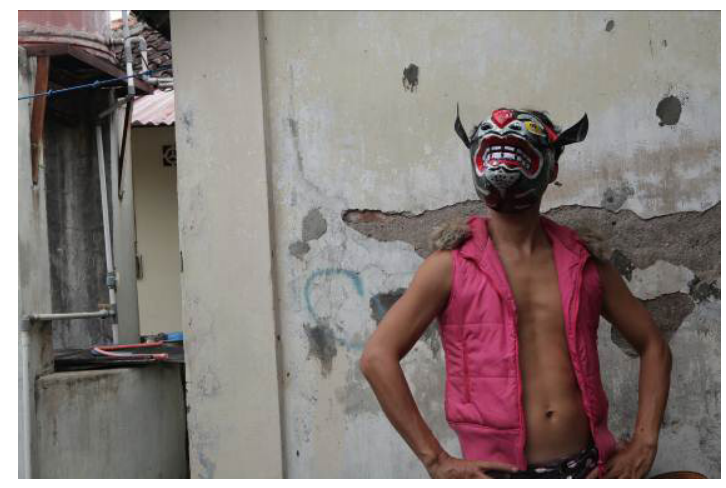

Gambar 6. Foto eksperimen karya pemotretan dengan cahaya matahari

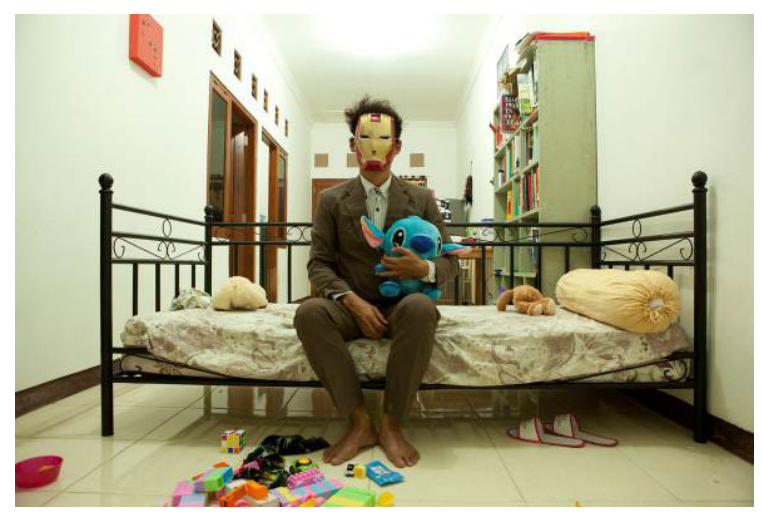

Gambar 7. Foto eksperimen karya pemotretan dengan cahaya lampu florence

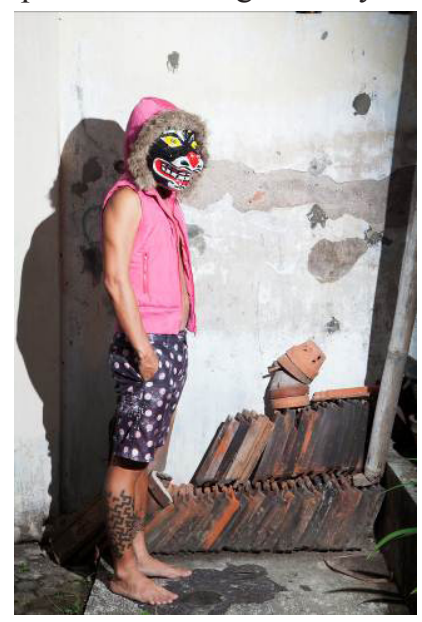

Gambar 8. Foto eksperimen karya pemotretan dengan cahaya Flash

Melalui proses eksperimen pemotretan dengan berbagai sumber cahaya, dipilih untuk menggunakan tehnik mix light, dengan cahaya flash (lampu kilat) sebagai main light-nya dan cahaya alami, matahari, sebagai fill-in light nya. Penentuan pemakaian sumber cahaya flash, karena cahaya keras yang dihasilkannya, sesuai dengan yang diinginkan oleh peneliti untuk membentuk karakter 'kebinatangan'. Sebagai proses akhir dalam kerangka kerja, dilakukan editing foto dengan menggunakan software Photoshop. Proses ini juga menjadi proses untuk melakukan 'finishing' untuk karya foto sebelum karya tersebut dicetak untuk dipresentasikan ke publik. Peneliti melakukan editing yang berbeda pada setiap foto karena adanya perbedaan jarak sumber cahaya main light dengan jarak objek pada saat pemotretan. Berikut adalah langkah-langkah proses editing 
yang dilakukan peneliti dengan menggunakan sofware Photoshop:

\section{b.1. Editing yang dilakukan pada foto no1.}

Editing yang dilakuakn oleh peneliti dalam karya no 1, menggunakan menu curve untuk menurunkan intensitas cahaya pada gambar. Selanjutnya, digunakan menu brightnes dan contrast untuk menambah terang dan kontras pada foto. Tool burning digunakan untuk menggelapkan bagian-bagian tertentu untuk mengangkat detail objek-objek tersentu seperti pada bagian tembok, topeng dan lantai.
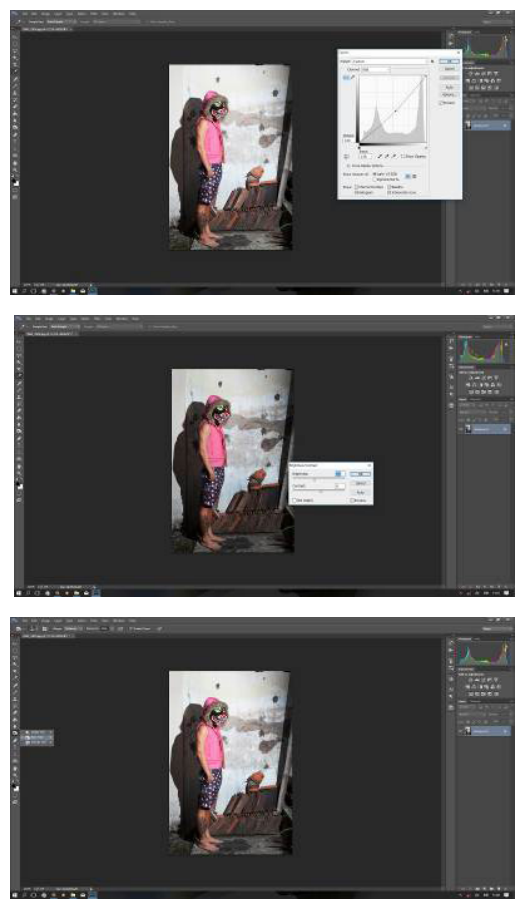

Gambar 9. Editing foto menggunakan photoshop

Pada karya no 1.

\section{b.2. Editing yang dilakukan pada foto no 2 .}

Pada karya no 2, peneliti melakukan editing foto dengan menu curve, brightnes, contrast dan pengaturan temperatur. Menu curve digunakan untuk menggelapkan foto secara global, sedangkan brightnes dan contrast digunakan untuk menambah kecerahan dan kontras pada foto. Pengaturan temperatur dilakukan untuk memperoleh kesan hangat dalam foto.
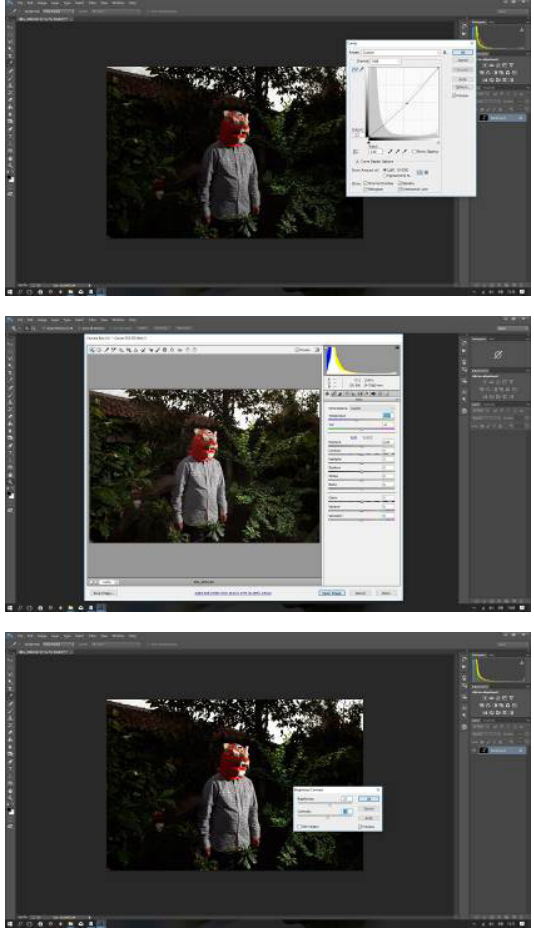

Gambar 10. Editing foto menggunakan photoshop Pada karya no 2.

b.3. Editing yang dilakukan pada foto no 3 .

Pada karya no 3, peneliti melakukan editing foto dengan menu curve dan tool burning. Menu curve digunakan untuk menggelapkan foto secara global.
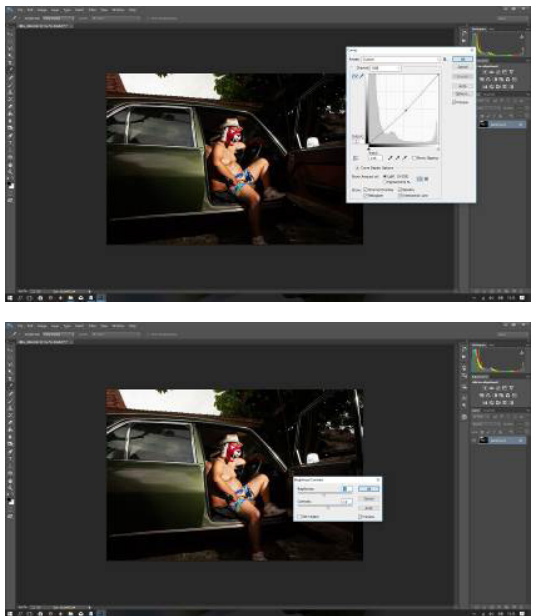

Gambar 11. Editing foto menggunakan photoshop Pada karya no 3.

b.4. Editing yang dilakukan pada foto no 4 . 
Pada karya no 4, peneliti menggunakan menu curve untuk menggelapkan secara global gambar. Setelah menggunakan menu curve, selanjutnya digunakan menu brightnes dan contrast untuk menambah terang dan contrast pada foto. Langkah selanjutnya menggunakan tool burning untuk menggelapkan bagian tertentu untuk menambah detail objek seperti topeng dan tubuh.
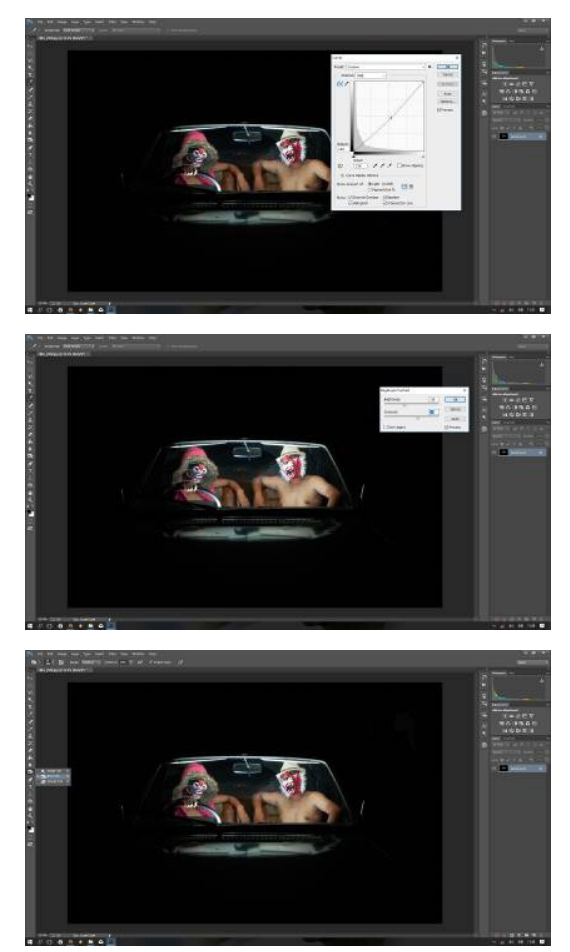

Gambar 12. Editing foto menggunakan photoshop Pada karya no 4.

\section{c) Pembentukan Karya}

Peneliti menganggap bahwa sebuah karya belum selesai seratus persen dari proses produksi apabila karya tersebut belum dipamerkan ke publik. Presentasi karya yang baik, merupakan bagian penting dan perlu untuk dipikirkan pada saat seorang seniman melakukan penciptaannya. Untuk itu, presentasi karya menjadi rangkaian proses yang diperhatikan dalam penelitian artistik ini. Senadan dengan hal tersebut di atas, Mike Susanto (2004), mengungkapkan bahwa pameran merupakan aksi perencanaan, penataan, perancangan, pengaturan, penyusunan berbagi unsur yang merupakan perangkat, tindakan atau sistem representasi dalam mengupayakan, mewujudkan dan menggagas serta berfungsi mendekatkan penonton pada wilayah kreatif seniman atau karya.

Untuk proses presentasi karya, hal pertama yang peneliti pertimbangkan adalah pilihan material yang digunakan dalam proses pencetakan karya, selain rencana penyajian karya untuk menentukan pengaturan karya dalam rangkaian satu kesatuan yang utuh serta mampu menyuarakan narasi seperti yang diharapkan. Sebagai bagian dari presentasi, peneliti memamerkan karyanya pada kegiatan Solo Photography Festival, yang digelar pada tanggal 9 November 2017 di Taman Budaya Jawa Tengah. Kegiatan Solo Photo Festival (SPF) ini dipilih karena acara reguler, mempunyai lingkup nasional serta telah dikenal di kalangan dunia fotografi Indonesia. Pada tahun yang lalu, acara SPF memperlihatkan jangkauan kerjasamanya dengan menggandeng seniman-seniman luarnegeri untuk berpameran bersama dengan mereka pada waktu itu.

Untuk material cetakan akan memakai kain kanvas. Peneliti memilih material tersebut karena tekstur yang dimilikinya dapat menambah nilai artistik karya. Kain kanvas juga mampu menyerap tinta cetak sehingga terlihat lebih kedap dan tidak menimbulkan refleksi cahaya yang dapat mengganggu pandangan pemirsa foto.

\section{B. Deskripsi Karya}

Paul Messaris (dalam Ajidarma, 2002: 26) mengungkapkan bahwa gambargambar yang diciptakan manusia, termasuk didalamnya fotografi, dapat dipandang sebagai keberaksaraan visual. Pandangan tersebut menjelaskan bahwa foto tidak hanya bisa dilihat dan diapresiasi dalam bentuk gambar semata, melainkan dapat dibaca seperti halnya sebuah teks. Gambar atau foto merupakan bahasa dari produk pikiran dan mewujud menjadi 
suatu produk kebudayaan, yang dari sana akan menghasilkan wacana pengetahuan.

Sebagai uraian dalam bab ini, pneliti melakukan aktivitas "membaca" foto untuk dijadikan deskripsi karya. Proses pembacaan menyandarkan pada konsepsi studium dan punctum yang terdapat pada foto karya peneliti. Barthes (dalam Ajidarma, ibid: 28), menjelaskan bahwa studium merupakan suatu kesan keseluruhan secara umum, yang akan mendorong seorang pemandang segera memutuskan apakah sebuah foto bersifat politis atau historis, indah atau tidak indah, yang membuat reaksi suka atau tidak suka. Sebaliknya dengan punctum, yang merupakan fakta terinci dalam sebuah foto yang menarik dan menuntut perhatian pemandang. Nilai yang dibawa dalam punctum inilah yang mengikat penonton untuk terus melihat maupun mengingat sebuah karya foto.

Sesuai dengan judulnya, peneliti mengunakan ketubuhannya sendiri sebagai model utama dalam karyanya. Tema yang dibuat dalam karya ini mengangkat sifat manusia dalam kehidupan sosialnya. Sifat yang dimaksud adalah sifat "kebinatangan" manusia dalam kehidupan sehari-hari yang disimbolkan oleh peneliti dengan menggunakan topeng binatang. Topeng biasanya dipakai oleh seorang aktor untuk memerankan suatu peran tertentu. Topeng membentuk simbol pesona yang tersembunyi di dalam kepribadian seseorang. Jung (dalam Schultz 1991), membagi pesona seseorang menjadi dua sisi, yaitu sisi negatif dan sisi positif. Pada sisi negatif terdapat bayang-bayang yang mengandung impuls yang dianggap jahat dan tak bermoral (baca:kebinatangan). Bayangbayang tersebut merupakan sisi gelap dalam diri manusia, yang apabila tidak ditekan maka impuls-impuls kebinatangan muncul dalam pesona manusia.

Selain menggunakan topeng sebagai elemen utama, dalam penciptaan karyanya peneliti juga memakai elemen pendukung untuk memperkuat simbolisasi dan bentukan visual dari karya yang dihasilkannya. Elemeneleman pendukung ini dipakai sebagai simbolisasi atas sifat ketertarikan duniawi manusia pada materi yang seringkali menjadi inti tujuan hidup manusia modern. Materi hidup tersebut mampu mengubah pesona manusia, bukan lagi menonjolkan sisi pesona manusiawinya, melainkan berubah menjadi pesona kebinatangan. Elemen pendukung yang digunakan antaralain, rompi, setelan formal dan mobil. Dalam tataran teknis, seperti yang sudah dijelaskan pada bagian sub bab eksperimen, peneliti menggunakan lampu flash dengan karakter cahaya yang keras. Karakter yang sejalan dengan gaya ungkap yang ingin dibangun oleh penulis, berkaitan dengan sifat kebinatangan manusia yang mempunyai karakter buas.

Sebagai hasil akhir yang akan dipresentasikan, peneliti mendapatkan empat karya foto. Keempat foto tersebut memiliki narasi tunggal yang mengungkapkan simbolisasi pesona kebinatangan manusia. Foto pertama, memperlihatkan manusia dengan topeng serigala yang menggunakan elemen pendukung baju rompi berwarna pink. Foto kedua, menggambarkan manusia yang menggunakan topeng macan dengan elemen pendukung jas resmi, sedangkan foto ketiga, manusia menggunakan topeng macan dengan elemen pendukung mobil. Foto terakhir, kedua manusia yang menggunakan topeng serigala dan macan dengan elemen pendukung mobil. Setting suasana yang di bentuk peneliti adalah suasana keseharian manusia, dengan bayangan bahwa ap sifat kebinatangan mnusia tidak pernah jauh dari realitas kehidupan personal dalam lingkup kesehariannya. Berikut adalah karya peneliti tentang pesona kebinatangan manusia: 


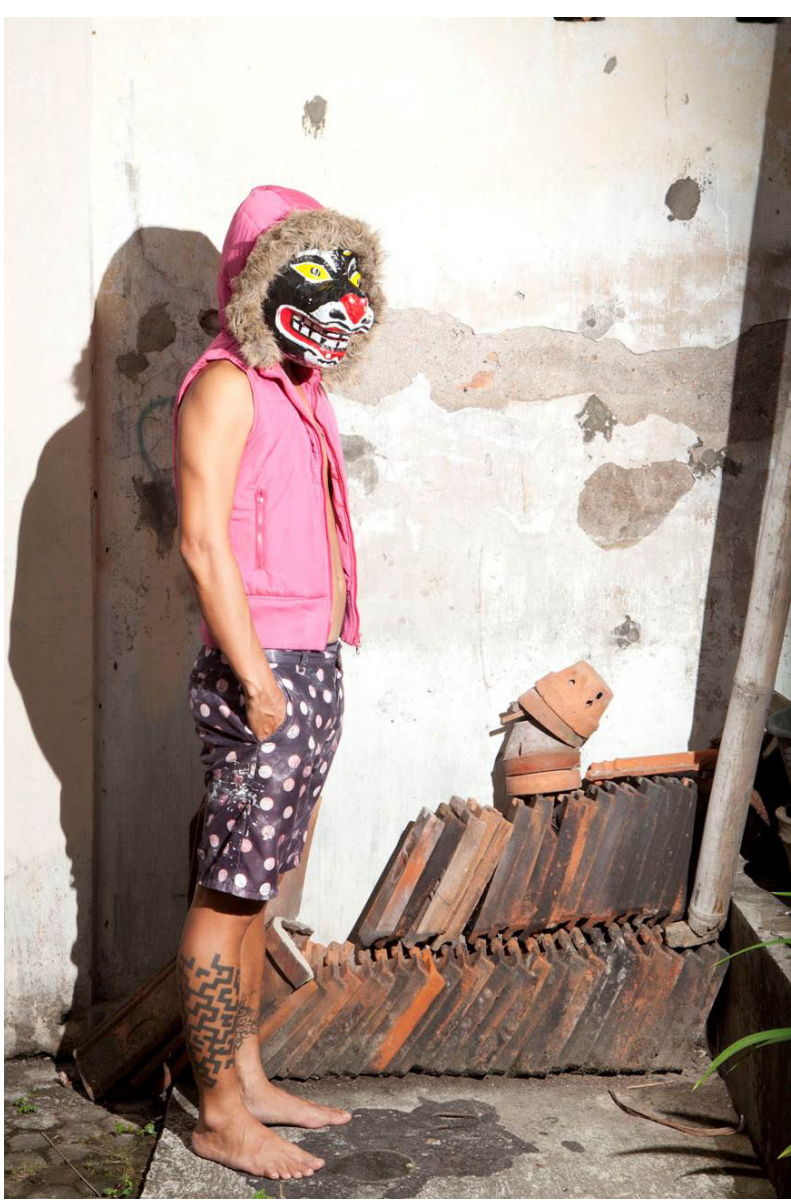

Gambar 13. Foto Karya 1

Pada foto no.1 model menggunakan topeng srigala sebagai elemen utamanaya. Untuk elemen pendukungnya, model menggunaan rompi merah muda dan celana pendek. Background foto yang dipilih adalah halaman belakang rumah.

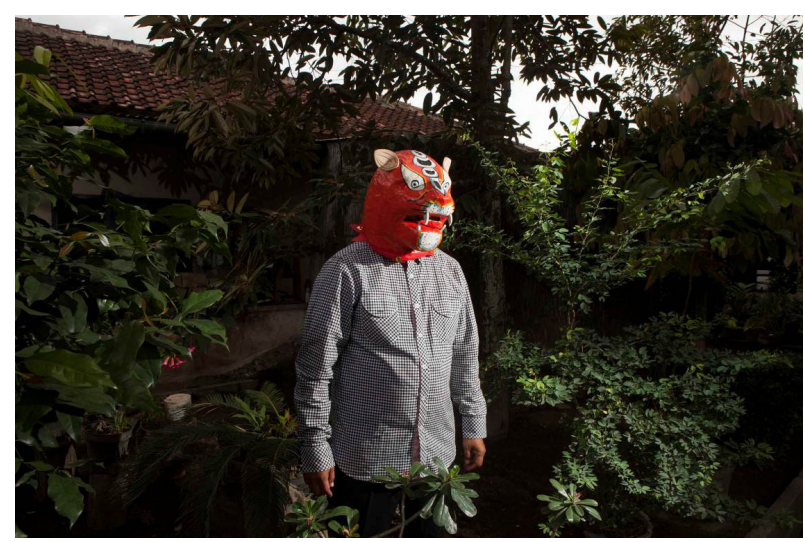

Gambar 14. Foto Karya 2

Pada foto no 2 model menggunakan topeng macan sebagai elemen utama. Sedangkan sebagai elemen pendukungnya, model menggunakan baju formal. Lokasi pemotretan yang dipilih adalah halaman rumah.

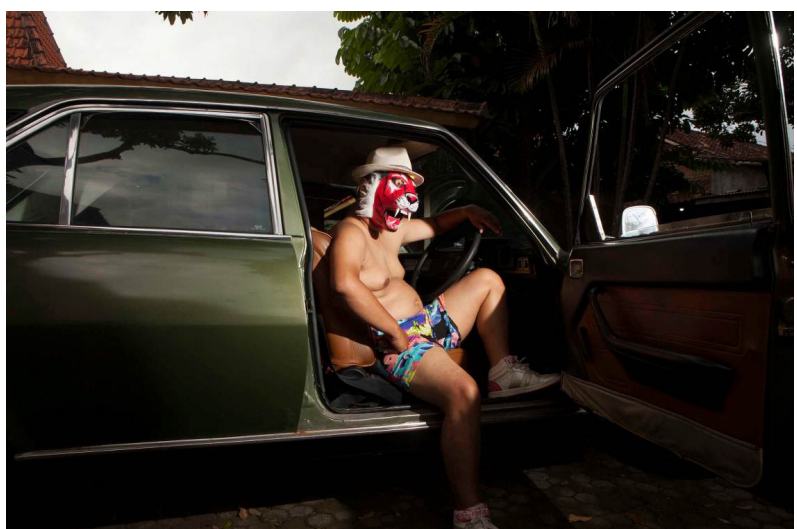

Gambar 15. Foto Karya 3

Pada foto no 3 model menggunakan topeng singa sebagai elemen utama dan sebagai elemen pendukungnya, model menggunakan celana pantai, sepatu putih dan mobil. Tempat foto yang dipilih adalah halaman rumah.

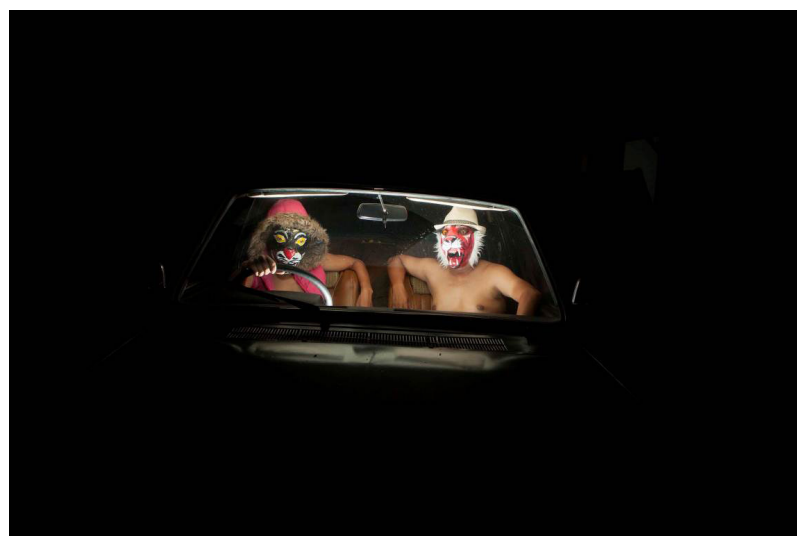

Gambar 16. Foto Karya 4

Pada foto no 4, kedua model menggunakan topeng singa dan srigala sebagai elemen utama dan sebagai elemen pendukungnya model menggunakan topi, rompi dan mobil. Tempat foto yang dipilih adalah di dalam mobil. 


\section{Simpulan}

$\begin{array}{llr}\text { Pada } & \text { saat membicarakan tentang } \\ \text { orisinalitas } & \text { dalam } & \text { penciptaan karya } \\ \text { seni, Fox } & (2012: & 6) \text { mengungkapkan }\end{array}$ ketidakpercayaannya terhadap adanya ide yang orisinal. Bagi Fox, semua gagasan telah bercampuraduk pada saat seniman melihat dan mempelajari suatu hal yang lain atau bahkan pada saat dia bereksperimen dengan material yang digunakannya. Kegagalan eksperimen yang memicu keberhasilan eksperimen yang lain, telah membuat jalinan yang rumit antar gagasan dalam praktek penciptaan karya seni. Untuk itu, peneliti juga merasa bahwa, ide penciptaan ini bukanlah suatu hal yang menjadi titik pusat penemuan proses kerja penelitian ini. Gagasan peneliti, disadari sangat dipengaruhi oleh berbagai temuan dalam proses panjang pembacaan terhadap referensi pustaka maupun karya acuan, interpretasi serta refleksi personal pasca pembacaan tersebut yang juga bercampur aduk dengan pengalaman pada saat melihat fenomena disekitarnya, selain juga eksperimen dengan material cetaknya.

Hal yang kemudian dapat ditawarkan dalam penelitian ini adalah masuknya unsur tradisional yang mengandung nuansa lokal yang memang sengaja dipilih untuk memperkuat karya fotografi ini. Pilihan atas latar dan properti yang digunakan dalam pengkaryaan ini, dilandasi oleh kesdaran bahwa sebuah karya foto memungkinkan untuk dibaca secara tekstual. Sehingga pilihan-pilihan atas kedua hal tersebut disengaja untuk digunakan untuk menarik punctum dari karya-karya foto yang dihasilkan. Gagasan atas sisi kebinatangan dalam diri manusia serta penggambaran dengan binatang karnivora sejenis macan dan serigala sebagai bentuk representasi atas 'kebuasan' mungkin juga dapat dibaca sebagai nuansa global. Akan tetapi, pemanfaatan latar yang bernuansa kehidupan lokal peneliti serta pelibatam properti berupa topeng kertas tradisional, yang secara produksi sudah mulai menghilang di pasaran menjadi nilai tambah terhadap karya foto tersebut.

Selain itu, unsur yang paling penting, yang ditawarkan dari hasil akhir penelitian ini adalah pengembangan kemampuan daya jelajah fotografi, selain sebagai medium yang menanpung kritik sosial, juga dapat digunakan sebagai alat untuk merefleksikan diri. Media yang dapat digunakan oleh masyarakat untuk melihat secara kritis, bayangan diri mereka dalam bentukan material visual foto. Praktek objektivifikasi tubuh yang dewasa ini menjadi semakin populer, merupakan suatu hal yang kemudian harus dilihat dalam perspektif kritis. Praktek subjektivikasi tubuh tanpa dilandasi kesadaran atas pola praktek perilakunya, dalam kesempatan yang memungkinkan untuk menumbuhkan tindakan kekerasan, baik secara fisik maupun tekanan psikologis yang tidak sehat terhadap tubuh sendiri. Di samping itu, praktek tersebut akan melanggengkan stereotipe yang terbangun atas tubuh, terutama terhadap perempuan, yang kemudian memberikan dampak ketidakseimbangan

\section{Daftar Pustaka}

Hamid, 2007. Meningkatkan Daya Fikir. Kuala Lumpur. PTS Publication \& Distributor Sdn, Bhd.

Calogero, RM. 2012. Objectification Theory, Self-objectification and Body Image. University of Kent. http://kar.kent. ac.uk/33425

Fox, Ana dan Natasha Caruna. 2012. Behind the Image; Research in Photography. Lausane. AVA Publishing SA

Gumira, Seno. 2002. Kisah Mata, Fotografi Antara Dua Subyek: Perbincangan Tentang Ada. Galang Press. Yogyakarta.

Oxford Dictionaries word of the year 2013 . 
Diambil dari http://blog.oxforddictionaries.com/ press-releases/oxford-dictionaries-word-of-theyear-2013.

Scultz, Duane. 1991. Psikologi Pertumbuhan, Model-Model Kepribadian Sehat. Kanisius. Yogyakarta.

Susanto, Mike. 2010. Menimbang Ruang Menata Rupa, Wajah dan Tata Pameran Seni Rupa. Galang Press. Yogyakarta.

Synott, Anthony. 2003. Tubuh Sosial: Simbolisme, Diri dan Masyarakat. Yogyakarta. Jalasutra.

Tedjoworo, H. 2010. Imaji dan Imajinasi, Suatu Telaah Filsafat Postmodern. Kanisius. Yogyakarta.

Wells, Liz. 1997. On and Beyond the White Walls dalam Liz Wells (Ed.) Photography: A Critical Introduction. London dan New York. Routledge.

\section{Data Internet:}

www.junocalypso.com/joyce-ii/ https://kbbi.web.id/buas https://adzelgar.wordpress.com/2009/02/02/ studi-dokumen-dalam-penelitian-kualitatif. http://www.itsnicethat.com/features/ones-to-watch2016-juno-calypso-photographer http://www.sleek-mag.com/2016/09/14/juno-calypso$\underline{\text { art/ }}$ 